\title{
Pathogenicity of a Novel Biotype of Limonomyces roseipellis in Tall Fescue
}

L. L. Burpee, Department of Plant Pathology, University of Georgia, Georgia Experiment Station, Griffin 30223; C. W. Mims, Department of Plant Pathology, University of Georgia, Athens 30602; L. P. Tredway, Department of Plant Pathology, North Carolina State University, Raleigh 27695; and J. Bae and G. Jung, Department of Plant Pathology, University of Wisconsin, Madison 53706

\begin{abstract}
Burpee, L. L., Mims, C. W., Tredway, L. P., Bae, J., and Jung, G. 2003. Pathogenicity of a novel biotype of Limonomyces roseipellis in tall fescue. Plant Dis. 87:1031-1036.

An unusual and undescribed foliar blight of tall fescue was observed in a home lawn and in turf grass research plots near Griffin, GA in May and June, 2000 and 2001. Isolation from lesions yielded mycelium of a basidiomycete with hyphal characteristics (binucleate cells, absence of clamp connections) associated with Laetisaria and Limonomyces spp. Isolates from blighted tall fescue and an isolate of Limonomyces roseipellis formed a clade distinct from isolates of Laetisaria fuciformis based on ribosomal DNA sequences. These data, in conjunction with cultural morphology, indicate that the basidiomycete from tall fescue represents a biotype of Limonomyces roseipellis that lacks clamp connections. In a controlled environment, isolates of the biotype induced foliar blight in the fescue cvs. Kentucky 31 and Rebel III. Histological observations revealed that the fungus colonized leaf surfaces as branched hyphae and aggregated hyphal strands. Penetration occurred via stomatal pores on the abaxial leaf surface. Colonization of leaf tissues was inter- and intracellular, with no evidence of papilla formation in response to invading hyphae. The name "cream leaf blight" is proposed for this new disease of tall fescue.
\end{abstract}

An unusual cream-colored foliar blight of tall fescue was observed in a home lawn near Griffin, GA in May 2000 (Fig. 1A). The 10-year-old lawn was composed of a blend of the tall fescue cvs. Rebel II and Tribute. Additional outbreaks were observed in May and June 2001 in tall fescue research plots, also near Griffin. Irregular, diffuse lesions, ranging in color from light yellow to white, formed at or near the apex of leaves (Fig. 1B). Lesions appeared to expand basipetally, consuming entire leaves and leaf sheaths. Some leaves were matted together with cream-colored mycelium. Foci of diseased leaves occurred throughout the lawn as gray-white patches as large as $45 \mathrm{~cm}$ in diameter.

Fungal hyphae, but no spores or sporocarps, were found associated with lesions and blighted leaves. Isolations from lesions yielded nonsporulating pink mycelium and aggregated hyphal strands. Hyphal cells were 2 to $6 \mu \mathrm{m}$ wide, binucleate with dolipore septa; clamp connections were absent. These characteristics, with the exception of the lack of clamp connections, suggested that the isolates were Limonomyces roseipellis Stalpers \& Loerakker (15), the cause of pink patch disease of turfgrass

Corresponding author: L. Burpee

E-mail: lburpee@gaes.griffin.peachnet.edu

Accepted for publication 21 April 2003.

Publication no. D-2003-0616-03R

(C) 2003 The American Phytopathological Society
(13). However, the hyphal characteristics of the isolates were also similar to those of another pink hymenomycete, Laetisaria fuciformis (McAlpine) Burdsall, which lacks clamp connections (2). The latter species causes red thread disease in turf grass swards (13).

Isolates of the unusual basidiomycete were collected for further study. Our objectives were to identify the fungus, evaluate pathogenicity, and examine the infection process.

\section{MATERIALS AND METHODS}

Identification of isolates. Two isolates of the pink, sterile basidiomycete were collected from blighted tall fescue grown near Griffin, GA. Isolate FB00-01 was obtained from a 10-year-old home lawn that had been seeded with a blend of the fescue cvs. Rebel II and Tribute. Isolate FB00-02 was collected from a 4-year-old sward of cv. Rebel III at the Georgia Agricultural Experiment Station, Griffin.

Morphological characteristics of cultures on potato-dextrose agar (PDA; Difco Laboratories, Detroit) were compared with a zoysia grass (Zoysia japonica Steud.) isolate (LR0088) of Limonomyces roseipellis collected by Stephen Vann, University of Arkansas, and two isolates (RT8 and RT10) of Laetisaria fuciformis collected by L. P. Tredway. The number of nuclei per hyphal cell was determined by following the fluorescent staining technique outlined by Martin (9). Secretion of laccase, required for lignin degradation, was detected visually by color changes of mycelium treated with $\alpha$-napthol (14). Isolates of $\mathrm{Li}$ monomyces roseipellis and Laetisaria fuciformis differ in reaction to $\alpha$-napthol (15).

Effect of temperature on hyphal growth rate was examined for each isolate. Plugs of hyphae ( $7 \mathrm{~mm}$ in diameter) were removed from the edges of colonies on PDA and transferred to the center of petri dishes containing approximately $20 \mathrm{ml}$ of PDA. The cultures were incubated in the dark at $10,12,15,18,20,25,28,32$, or $35^{\circ} \mathrm{C}$ and radial growth of colonies was measured after 19, 45, and $67 \mathrm{~h}$ of incubation. Mean radial growth rate $\left(\mathrm{mm} \mathrm{h}^{-1}\right)$ was calculated from three replicate cultures at each temperature. The experiment was repeated once.

To assist in identification of the sterile basidiomycete, ribosomal (r)DNA sequences from isolates FB00-01 and FB0002 and isolates of Limonomyces roseipellis and Laetisaria fuciformis were analyzed independently in laboratories at North Carolina State University (NCSU) and The University of Wisconsin (UW). In the NCSU study, polymerase chain reaction (PCR) amplification of rDNA internal transcribed spacer (ITS) regions ITS1, 5.8S rRNA, and ITS2 was performed using primers ITS5 and ITS4 (16). PCR reactions were $50 \mu \mathrm{l}$ in volume and consisted of $20 \mathrm{mM}$ Tris- $\mathrm{HCl}$ (pH 8.3), $50 \mathrm{mM} \mathrm{KCl}$, $1.5 \mathrm{mM} \mathrm{MgCl} 2,200 \mu \mathrm{M}$ each dNTPs, 200 $\mathrm{nM}$ of each primer, $1.5 \mathrm{U}$ of Taq polymerase (Invitrogen Corp., Carlsbad, CA), and $50 \mathrm{ng}$ of genomic DNA. Thermal cycling conditions involved an initial denaturation step at $95^{\circ} \mathrm{C}$ for $3 \mathrm{~min}$, followed by 33 cycles of $95^{\circ} \mathrm{C}$ for $30 \mathrm{~s}, 58^{\circ} \mathrm{C}$ for $1 \mathrm{~min}$, and $72^{\circ} \mathrm{C}$ for $45 \mathrm{~s}$, and a final extension step at $72^{\circ} \mathrm{C}$ for $10 \mathrm{~min}$. Amplification products were purified with a Qiaquick PCR Purification Kit (Qiagen Inc., Valencia, CA). Cycle sequencing reactions were performed using an ABI Prism BigDye Terminator v3.0 Ready Reaction Cycle Sequencing Kit (Applied Biosystems Inc., Foster City, CA). Reactions were run on a Perkin-Elmer ABI Prism 310 or 3700 DNA sequencer (Applied Biosystems Inc.) following the removal of unincorporated dye using Centrisep columns (Princeton Separations Inc., Adelphia, NJ). Sequences homologous to those from FB00-01 and FB00-02 were identified through a BLAST search of the GenBank database (National Center for Biotechnology Information). All sequences were aligned using the ClustalW 
method in MegAlign 5.05 (DNASTAR Inc., Madison, WI) and adjusted by visual examination. A phylogenetic tree was constructed in MEGA 1.02 (8) using the Neighbor-Joining algorithm from genetic distances calculated using the Kimura Two-Parameter Model. Bootstrap values were calculated in MEGA 1.02 based on 1,000 random samples of the data set.

In the UW study, the complete (C)ITS region of nuclear ribosomal (nr)DNA of isolates FB00-01 and FB00-02, isolates RT8 and RT10 of Laetisaria fuciformis, and isolate LR0088 of Limonomyces roseipellis was amplified by the PCR reaction with the CITS primers ITS-1 and ITS4 (16). The PCR product then was inserted into a plasmid and amplified in Escherichia coli (11). The plasmid DNA was isolated from the bacterium (5) and the PCR insert was sequenced at the DNA Sequence Laboratory, University of Wisconsin Biotechnology Center, Madison.

Pathogenicity studies. Pathogenicity and virulence of isolates FB00-01 and FB00-02 were assessed on tall fescue plants in a controlled environment. Tall fescue cvs. Kentucky 31 and Rebel III were grown from seed in a greenhouse in 10-cm-diameter plastic pots containing

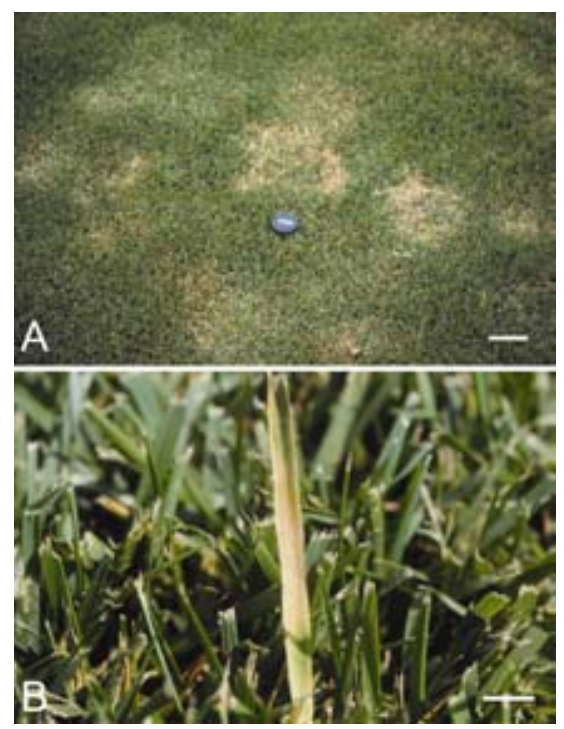

Fig. 1. Foliar blight of tall fescue observed in a home lawn near Griffin, GA in May 2000. A, Patches of chlorotic to white foliage. Bar $=10$ $\mathrm{cm}$. B, Diffuse chlorotic to white lesion on tall fescue leaf. $B a r=1 \mathrm{~cm}$. granular calcined clay (Turface, Applied Industrial Materials Corp., Deerfield, IL). Each pot was seeded at a rate equivalent to $244 \mathrm{~kg} \mathrm{ha}^{-1}$, then watered daily and fertilized every 14 days with a solution containing $\mathrm{N}, \mathrm{P}$, and $\mathrm{K}$ at 434, 99, and $373 \mathrm{ppm}$, respectively. The turf was cut with scissors weekly to a height of approximately 6.5 $\mathrm{cm}$. Temperatures in the greenhouse ranged from 24 to $30^{\circ} \mathrm{C}$ in the day and 14 to $22^{\circ} \mathrm{C}$ at night. No supplemental lighting was used.

Inoculum was prepared by culturing isolates FB00-01 and FB00-02 separately on autoclaved rye grain (3) for 3 weeks at $23^{\circ} \mathrm{C}$. Six-week-old tall fescue was inoculated by placing approximately $2 \mathrm{~g}$ of infested grain within the turf foliar canopy in the center of each pot. Four pots of each cultivar were inoculated, and four pots of each served as noninoculated controls. Immediately after inoculation, the turf foliage was misted with water to runoff, and each pot was placed in a translucent plastic bag. Each pot contained three plastic pot markers, placed in the Turface along the pot rim about $6 \mathrm{~cm}$ apart, to prevent the plastic bag from collapsing onto the turf canopy. Pots were placed in a plant growth chamber in a completely randomized design under light at $14 \mathrm{~h} \mathrm{day}^{-1}$ (photon flux density $=350 \mu \mathrm{E} \mathrm{m}^{-2} \mathrm{~s}^{-1}$ ) at $29^{\circ} \mathrm{C}$ and $10 \mathrm{~h}$ of dark at $24^{\circ} \mathrm{C}$. Maximum temperatures were 32 and $24^{\circ} \mathrm{C}$ within the plastic bags during light and dark phases, respectively. At $3,7,10,13,16$, and 20 days post inocu- lation, plastic bags were removed and disease severity (proportion of necrotic foliage per pot) was estimated visually using the Horsfall-Barratt rating scale (6). Foliage was misted with water and the plastic bags were replaced after each of the initial five rating intervals. Disease severity values were subjected to analysis of variance using Statistical Analysis Software (SAS Institute Inc., Cary, NC) and means were separated by cluster analysis (12) at $\alpha=$ 0.05 . The experiment was repeated once.

Infection and colonization. Samples of tall fescue foliage, inoculated with isolate FB00-01, were examined with light and electron microscopy to observe infection and colonization processes. Tall fescue cv. Rebel III was grown from seed in a greenhouse and inoculated as described in the pathogenicity section. At 3 days post inoculation, leaves contacted by hyphae spreading outward from inoculum were cut through the leaf sheath with a small pair of scissors and removed from pots. Green leaves showing little if any evidence of disease as well as those showing obvious chlorosis and necrosis were sampled. Excised leaves were cut into strips measuring approximately 2 to 3 by 4 to $5 \mathrm{~mm}$ using a sharp double-edged razor blade and placed in fixative consisting of $2.5 \%$ glutaraldehyde in $100 \mathrm{mM}$ phosphate buffer at $\mathrm{pH}$ 6.8. After approximately $12 \mathrm{~h}$ at $4^{\circ} \mathrm{C}$, this solution was pipetted off and the samples were washed in phosphate buffer for 15 min, then placed in similarly buffered $1 \%$

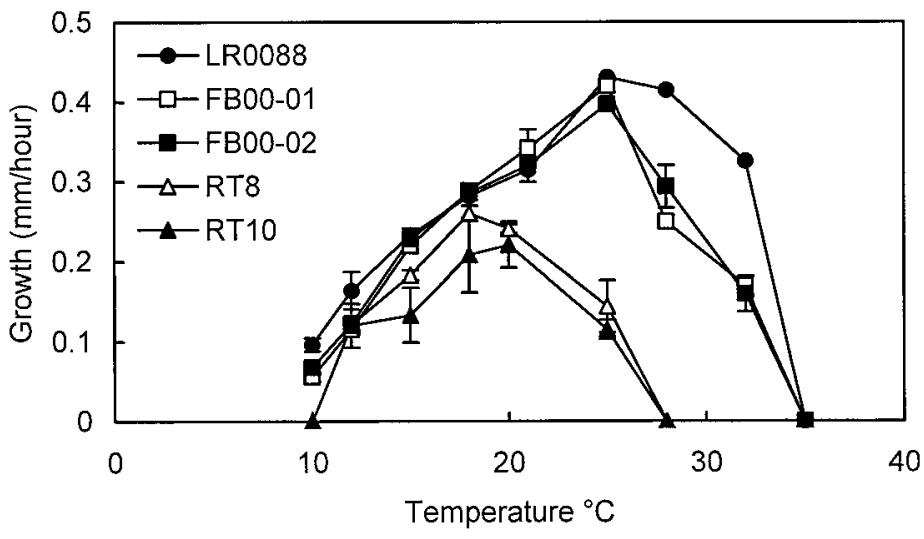

Fig. 2. Effect of temperature on radial growth rate of isolates of Limonomyces roseipellis (LR0088), the sterile basidiomycete associated with foliar blight of tall fescue (FB00-01 and FB00-02), and Laetisaria fuciformis (RT8 and RT10) on potato-dextrose agar. Vertical bars represent standard errors based on six replicates.

Table 1. Comparison of morphological and other characteristics of isolates FB00-01 and FB00-02 from blighted tall fescue with those of Limonomyces roseipellis and Laetisaria fuciformis

\begin{tabular}{lll}
\hline Tall fescue isolates & \multicolumn{1}{c}{ Limonomyces roseipellis $^{\mathbf{a}}$} & Laetisaria fuciformis $^{\mathbf{a}}$ \\
\hline Pink mycelium, dolipore $(\mathrm{dp})$ septa, thin hyphal & Pink mycelium, dp septa, thin hyphal strands & Pink mycelium, dp septa, thick, branched hy- \\
strands but no red threads $\mathrm{b}$ & but no red threads & phal strands (red threads) \\
Binucleate hyphal cells, diameter 1.5-6.0 $\mu \mathrm{m}$, & Binucleate hyphal cells, diameter 1-7 $\mu \mathrm{m}$, & Multinucleate hyphal cells, diameter \\
clamps absent & clamps present & $3.5-10 \mu \mathrm{m}$, clamps absent \\
No arthroconidia observed & Arthroconidia rare & Forms arthroconidia \\
Laccase reaction, strong & Laccase reaction, strong & Laccase reaction, weak \\
\hline
\end{tabular}

\footnotetext{
a From description given in Stalpers and Loerakkers (15).

${ }^{\mathrm{b}}$ Red threads (thick, branched hyphal strands) may form at low temperatures $\left(10\right.$ to $\left.12^{\circ} \mathrm{C}\right)$.
} 
$\mathrm{OsO}_{4}$ for $2 \mathrm{~h}$ at $4^{\circ} \mathrm{C}$. Following removal of the $\mathrm{OsO}_{4}$ solution, samples were rinsed in multiple changes of distilled water for a total of $30 \mathrm{~min}$ and stained overnight in $0.05 \%$ aqueous uranyl acetate. Samples then were prepared for examination with either scanning electron microscopy (SEM) or transmission electron microscopy (TEM) according to the procedures of Mims and Vaillancourt (10). Samples for SEM were examined and photographed using a JEOL scanning electron microscope (JEOL, Akishima, Japan) operating at $15 \mathrm{kV}$. Thin sections of samples prepared for TEM were examined and photographed using a Zeiss 902A transmission electron microscope (Carl Zeiss, Göttingen, Germany) operating at $80 \mathrm{kV}$. For light microscopy, 1- $\mu$ m-thick sections of resin-embedded leaves were cut with a diamond knife, collected on glass microscope slides, stained with toluidine blue $\mathrm{O}$, and examined and photographed with bright field microscopy.

\section{RESULTS}

Identification of isolates. No signs of a teleomorph were found associated with blighted tall fescue, and attempts to induce sporulation in vitro failed. With the exception of an absence of clamp connections, the mycelial characteristics of the tall fescue isolates were more closely aligned with those of Limonomyces roseipellis than with Laetisaria fuciformis (Table 1).

Effects of repeated trials on radial growth rate were not significant. Therefore, data were combined and analyzed as one data set. At $15^{\circ} \mathrm{C}$ or higher, radial growth rates for isolates FB00-01 and FB00-02 were more similar to those recorded for isolate LR0088 of Limonomyces roseipellis than to rates recorded for either isolate of Laetisaria fuciformis tested (Fig. 2). At all temperatures except $12^{\circ} \mathrm{C}$, radial growth rates were greater for isolates FB00-01, FB00-02 and LR0088 than for either isolate RT8 or RT10 of L. fuciformis. Isolates RT8 and RT10 failed to grow at temperatures $\geq 28^{\circ} \mathrm{C}$, whereas the tall fescue isolates and LR0088 grew at temperatures as high as $32^{\circ} \mathrm{C}$. The most rapid radial growth (approximately $0.4 \mathrm{~mm} \mathrm{~h}^{-1}$ ) was recorded at $25^{\circ} \mathrm{C}$ for the tall fescue isolates and LR0088. Peak growth rates for isolates RT8 and RT10 of L. fucisformis occurred at 18 and $20^{\circ} \mathrm{C}$, respectively.

In the NCSU sequence study, unaligned sequences of the ITS1, 5.8S, and ITS2 regions were 638 and 639 bases in length from isolates FB00-01 and FB00-02, respectively. The unaligned sequence from isolate LR0088 was 611 bases long, whereas sequences from isolates RT4, RT8, and RT10 were 631, 643, and 625 bases in length, respectively. A BLAST search of the GenBank database identified no entries with similarity to the ITS1 and ITS2 regions from FB00-01 or FB00-02. The conserved 5.8S region from FB00-01 and FB00-02 was highly similar (E-value $\geq$ $4 \times 10^{-80}$ ) to several genera of hymenomycetes, including Cryptococcus, Tricholoma, Typhula, and Entoloma (data not shown). A sequence from Entoloma nitidum (GenBank accession no. AF335449) was downloaded to serve as an outgroup for phylogenetic analysis of sequences from Limonomyces roseipellis, Laetisaria fuciformis, and the unknown isolates FB00-01 and FB00-02.

\section{$\mathbf{A}$}
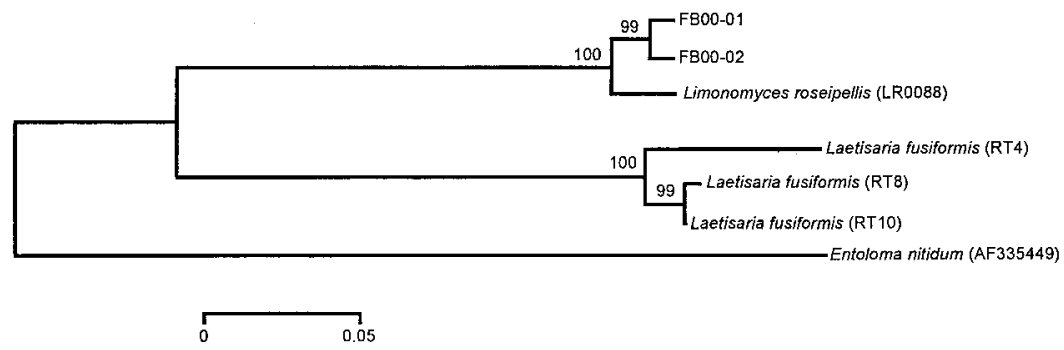

B

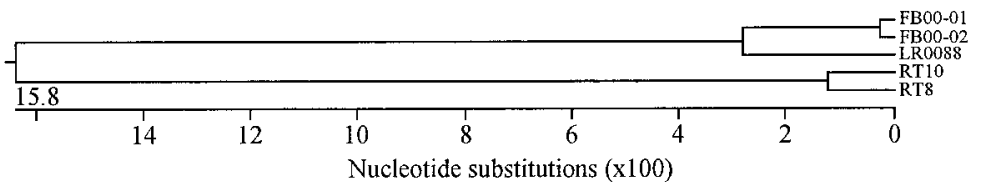

Fig. 3. Phylogenetic trees drawn from the nucleotide sequences of the internal transcribed (ITS) region of ribosomal DNA from Limonomyces roseipellis (isolate LR0088), Laetisaria fuciformis (isolates RT4, RT8, and RT10), and the tall fescue blight basidiomycete (isolates of FB00-01 and FB00-02). A, Tree constructed by the Neighbor-Joining algorithm on sequence data from North Carolina State University. Entoloma nitidum was employed as the outgroup. B, Tree constructed by DNAStar Cluster method with weighted residue on data from the University of Wisconsin. DNA from isolate RT4 was not sequenced at this site.

Table 2. Genetic distance matrix based on sequence data from the internal transcribed spacer (ITS)1, 5.8S rRNA, and ITS2 regions of the rDNA locus from Limonomyces roseipellis (LR0088), Laetisaria fuciformis (RT4, RT8, and RT10) and the sterile basidiomycete isolated from tall fescue (FB00-01 and FB00-02) ${ }^{\mathrm{a}}$

\begin{tabular}{lcccccc}
\hline & AF335449 $^{\mathbf{b}}$ & RT4 & RT8 & RT10 & FB00-01 & FB00-02 \\
\hline LR0088 & 0.4662 & 0.3709 & 0.3231 & 0.3206 & 0.0385 & 0.0439 \\
AF335449 & $\ldots$ & 0.5052 & 0.4874 & 0.4843 & 0.4718 & 0.4638 \\
RT4 & $\ldots$ & $\ldots$ & 0.0695 & 0.0676 & 0.3648 & 0.3761 \\
RT8 & $\ldots$ & $\ldots$ & 0.0017 & 0.3146 & 0.3252 \\
RT10 & $\ldots$ & $\ldots$ & $\ldots$ & $\ldots$ & 0.3226 \\
FB00-01 & $\ldots$ & $\ldots$ & $\ldots$ & $\ldots$ & $\ldots$ \\
FB00-02 & $\ldots$ & $\ldots$ & $\ldots$ & $\ldots$ & $\ldots$ \\
\hline
\end{tabular}

\footnotetext{
${ }^{a}$ Genetic distances were calculated using the Kimura Two-Parameter Model.
}

${ }^{\mathrm{b}}$ Entoloma nitidum (AF335449) was employed as an outgroup. 
gence. The two CITS sequences from isolates RT8 and RT10 of L. fuciformis were $87.4 \%$ identical, with a $2.5 \%$ divergence. The sequences from isolates FB00-01 and FB00-02 were 82.4 to $81.9 \%$ identical to the sequence of Limonomyces roseipellis (isolate LR0088) and 37.3 to $35.7 \%$ identical to isolates RT8 and RT10 of Laetisaria fuciformis.

Pathogenicity. Isolates FB00-01 and FB00-02 incited foliar blight of tall fescue cvs. Rebel III and Kentucky 31 (Fig. 4A and B). Differences between trials were not significant; therefore, data were combined and analyzed. No significant difference $(P$ $>0.05)$ was detected in virulence between the two isolates on either cultivar. Over a 3 -week period, disease progressed to an intensity where approximately 50 to $60 \%$ of turf foliage was blighted. Symptoms were identical to those observed in the blighted tall fescue swards in 2000 and 2001. Chlorotic to white foliar lesions developed as hyphae grew from the inoculum source over the surface of leaves. Epiphytic mycelium appeared hyaline to white and did not aggregate to form stromata or sclerotia. No fructifications or spores were observed on or in diseased tissue.

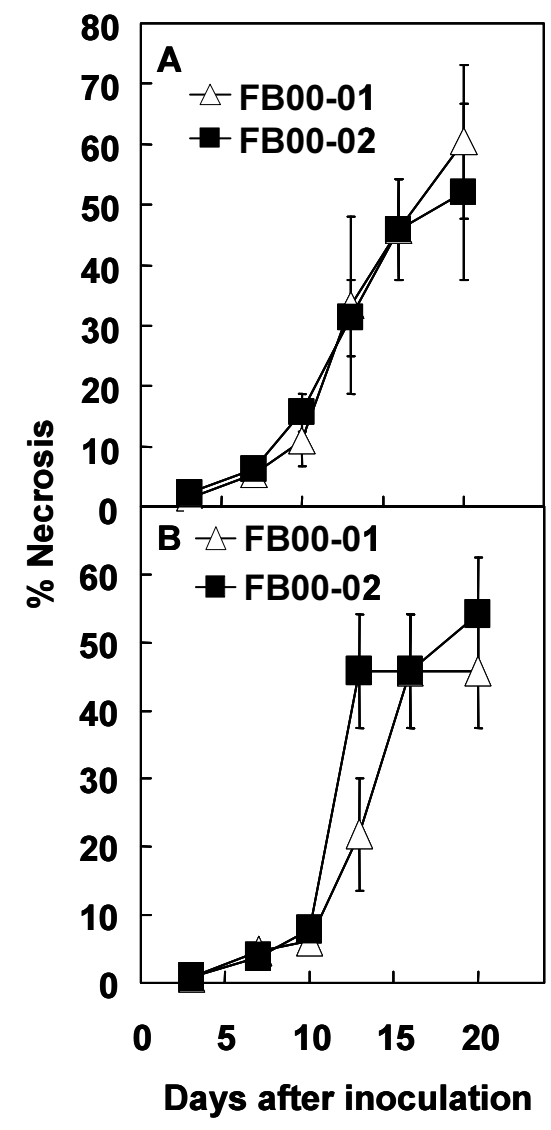

Fig. 4. Percentage of necrotic foliage in pots of tall fescue inoculated with either isolate FBO001 or FB00-02 of the sterile basidiomycete isolated from blighted tall fescue. Inoculated plants were incubated in a controlled environment with $14 \mathrm{~h}$ of light at $29^{\circ} \mathrm{C}, 10 \mathrm{~h}$ of dark at $24^{\circ} \mathrm{C}$, and continuous leaf wetness. A, Cv. Kentucky 31. B, Cv. Rebel III.
Infection and colonization. Hyphae of isolate FB00-01 spread out from the infested grain used as inoculum over the surfaces of surrounding leaves of the tall fescue plants. Fungal mycelium on leaves was visible with the naked eye, appearing as a fuzzy, glistening, cream-colored growth that extended from leaf to leaf. This mycelium possessed considerable tensile strength and tended to bind adjacent leaves. SEM (Fig. 5) revealed that a sparse system of branched hyphae spread over the surfaces of a contacted host leaf (Fig. 5A). However, a dense coating of hyphae subsequently developed on host leaves (Fig. $5 \mathrm{~A}-\mathrm{D})$. As is evident in Figure $5 \mathrm{C}$ and $\mathrm{D}$, hyphae often formed conspicuous strandlike aggregations. Hyphae appeared to enter leaves by growing into stomatal pores on the abaxial leaf surface (Fig. 5B).

Data from light-microscopic examination of thin sections of resin-embedded samples stained with toulidine blue O (Fig. 6) confirmed our observations with SEM. In particular, pathogen ingress via stomatal openings on abaxial leaf surfaces was commonly observed (Fig. 6C and D). Light microscopy also revealed that, once hyphae entered the intercellular spaces adjacent to stomatal pores, they then spread throughout the entire leaf, growing not only between host cells but also into and completely through many cells (Fig. 6D).

Observations with TEM failed to reveal any evidence of host cell wall response to invading hyphae (Fig. 7A and B). Not a single papilla was observed at any of the
23 penetration sites we observed. Hyphae were greatly constricted at host cell penetration sites (Fig. 7A and B). TEM (Fig. 7C) showed that the hyphae of isolate FB00-01 were septate but lacked clamp connections. Longitudinal sections of hyphae revealed that the septa were of the dolipore type (Fig. 7 D). The septal pore cap associated with each septum was perforated (Fig. 7D).

Though not apparent in scanning electron micrographs (Fig. 5), observation of light micrographs (Fig. 7B and C) suggested that masses of hyphae present on adaxial leaf surfaces often were coated with a layer of extracellular material. Closer examination of hyphae with TEM confirmed the presence of this material on all external hyphae of isolate FB00-01. Although usually very faint and difficult to resolve in most sections (Fig. 7E), this material was much more apparent when slightly thicker sections of hyphae were examined with TEM (Fig. 7F and G). In thicker sections (Fig. 7F and G), this extracellular material was electron dense and finely fibrillar in appearance.

\section{DISCUSSION}

Morphological and physiological characteristics indicate that, despite the absence of clamp connections, the pink basidiomycete associated with foliar blight of tall fescue in Georgia was more closely related to Limonomyces roseipellis than to Laetisaria fuciformis. This association was supported by analysis of rDNA sequences. In

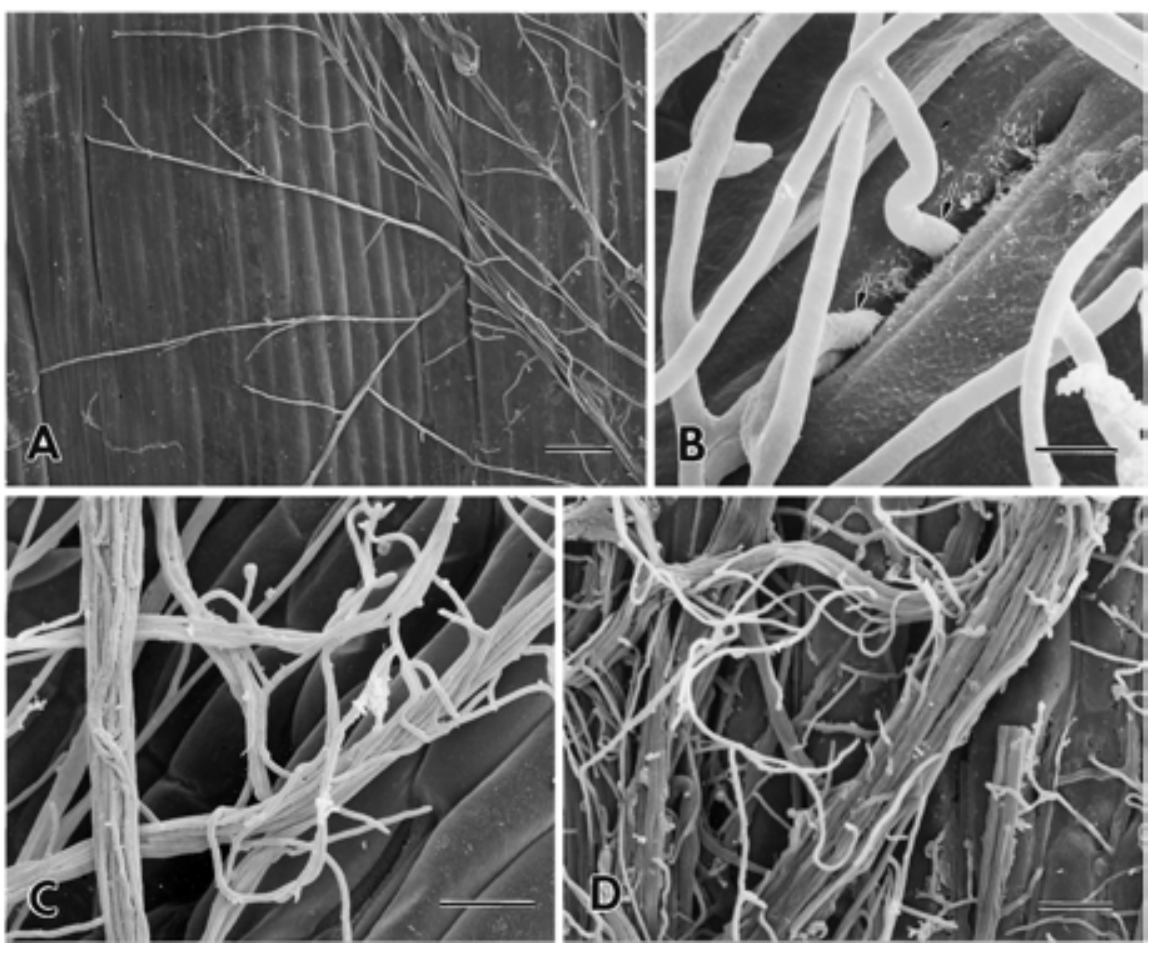

Fig. 5. Scanning electron micrographs of hyphae of isolate FB00-01 on leaves of tall fescue cv. Rebel III. A, Hyphae on the abaxial surface of a leaf early in the infection process. Bar $=50 \mu \mathrm{m}$. B, Hyphae entering a stomatal pore on the abaxial surface of a leaf. Bar $=5 \mu \mathrm{m}$. C, Strands of aggregated hyphae on the abaxial surface of an infected leaf. Bar $=20 \mu \mathrm{m}$. D, Hyphal strands on the adaxial surface of an infected leaf. Bar $=20 \mu \mathrm{m}$. 
the wake of further evidence (e.g., identification of a teleomorph or DNA sequence data from additional isolates), we conclude that isolates FB00-01 and FB00-02 represent a biotype of Limonomyces similar to Limonomyces roseipellis. The host range and geographical distribution of this fungus is currently unknown.

In the pathogenicity study, signs and symptoms of disease caused by the biotype of Limonomyces were similar to those observed in swards of tall fescue, but distinct from symptoms of pink patch caused by $L$. roseipellis $(13,15)$. As the name implies, pink patch is characterized by leaves that are "covered with a pink, gelatinous growth of mycelium" (13). This sign was not observed on tall fescue in the field or in a controlled environment. Lesions and epiphytic mycelium on fescue were white; similar to those associated with white patch disease caused by Melanotus philip- sii (Berk. \& Br.) Singer (4). In fact, the disease initially was diagnosed as white patch (L. L. Burpee, unpublished data) although the typical sporocarps of M. philipsii (4) were not observed on shoots or foliage (L. L. Burpee, unpublished data).

Given the unique qualities of the pathogen and the novelty of signs and symptoms, we propose the name "cream leaf blight" for the disease of tall fescue caused by the "clampless" biotype of $L$. roseipellis. We warn, however, that the absence of pink coloration associated with Limonomyces-infected tall fescue may be temperature related. Observations of cream leaf blight in the field and in controlled environment were made at temperatures near $30^{\circ} \mathrm{C}$. We noted a loss of pink pigmentation in mycelium in vitro at elevated temperatures which may explain an absence of color associated with diseased foliage. Therefore, although no observations support this, it is possible that signs and symptoms of cream leaf blight may be similar to those described for pink patch if the former disease occurs at temperatures $<30^{\circ} \mathrm{C}$.

Temperature optima similar to those recorded for isolates RT8 and RT10, as well as a failure to grow at 28 to $30^{\circ} \mathrm{C}$, have been observed for Corticium fuciforme (Berk.) Wakef. (= Laetisaria fuciformis; 3) $(1,15)$. In addition, Kaplan and Jackson (7) reported that turf grass isolates of $L$. fuciformis failed to grow at $27.5^{\circ} \mathrm{C}$, but isolates of Athelia fuciformis (Wakef.) Burds. (= Limonomyces roseipellis; 15$)$ grew well at this temperature. These observations support our findings and suggest that the responses of isolates FB00-01 and FB0002 to changes in temperature in vitro are more similar to those reported for $L$. roseipellis than for Laetisaria fuciformis.

Our study appears to be the most detailed investigation, to date, of infection
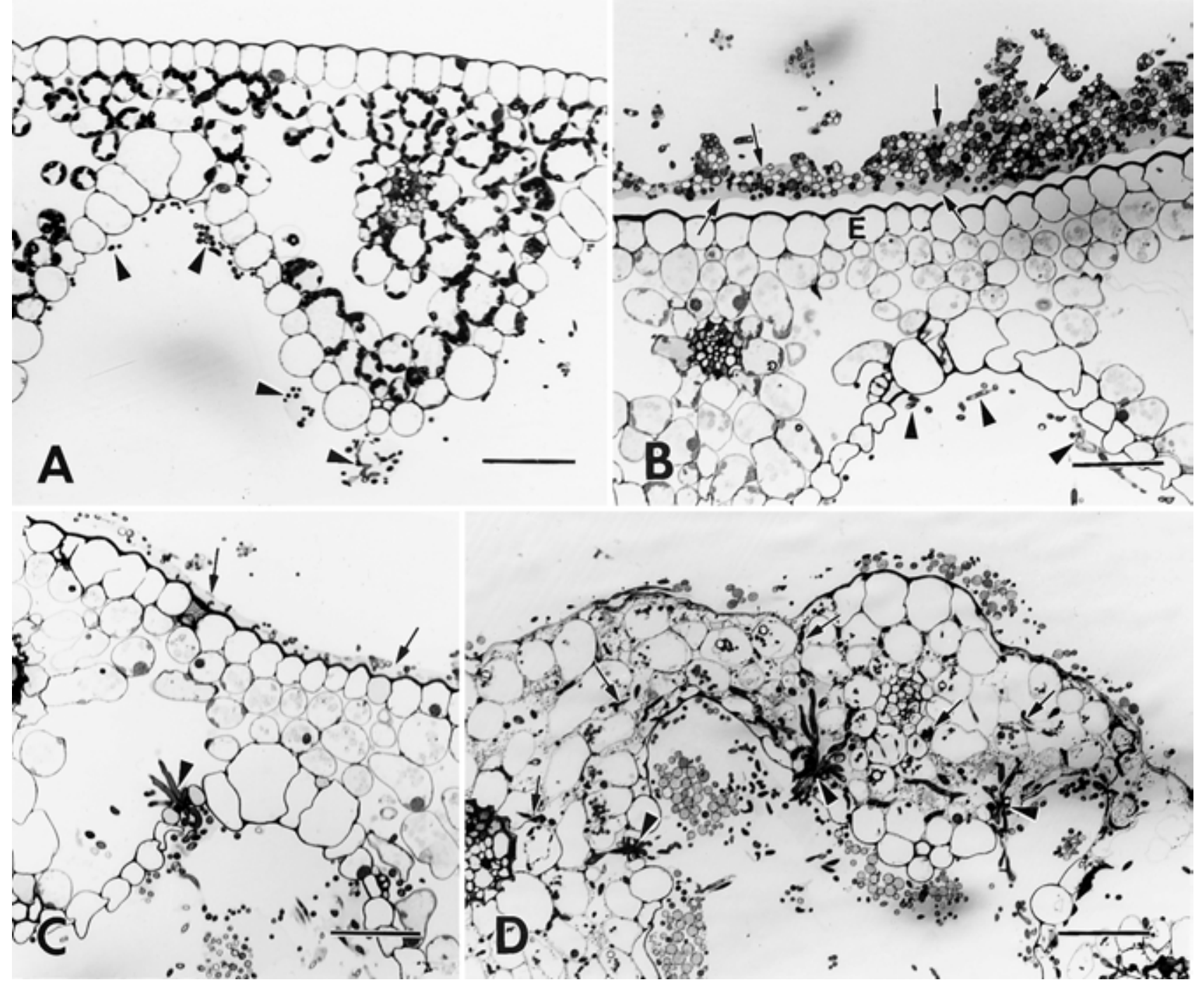

Fig. 6. Light micrographs of 1- $\mu$ m thick sections of resin-embedded samples stained with toulidine blue O. A, Portion of a leaf prior to infection by isolate FB00-01. Cross sections of a few hyphae (arrowheads) of the pathogen are visible on the abaxial leaf surface. Bar $=50 \mu \mathrm{m}$. B, Portion of a leaf whose adaxial surface is covered by a thick layer of hyphae. These hyphae appear to be embedded in a layer of extracellular material (arrows). In this sample, the hyphae and extracellular material have separated slightly from the leaf epidermis (E). A few hyphae (arrowheads) are visible on the abaxial leaf surface. Bar $=50 \mu \mathrm{m}$. C, Example of hyphae (arrowhead) that have entered a leaf via a stomatal pore. A thin layer of extracellular material (arrows) covers the hyphae present on the adaxial leaf surface. Bar $=50 \mu \mathrm{m}$. D, Example of a leaf that has been over run with hyphae of isolate FB00-01. Hyphae are particularly prominent near stomatal pores (arrowheads) where ingress occurred but also are evident elsewhere in the leaf (arrow). Bar $=50 \mu \mathrm{m}$. 


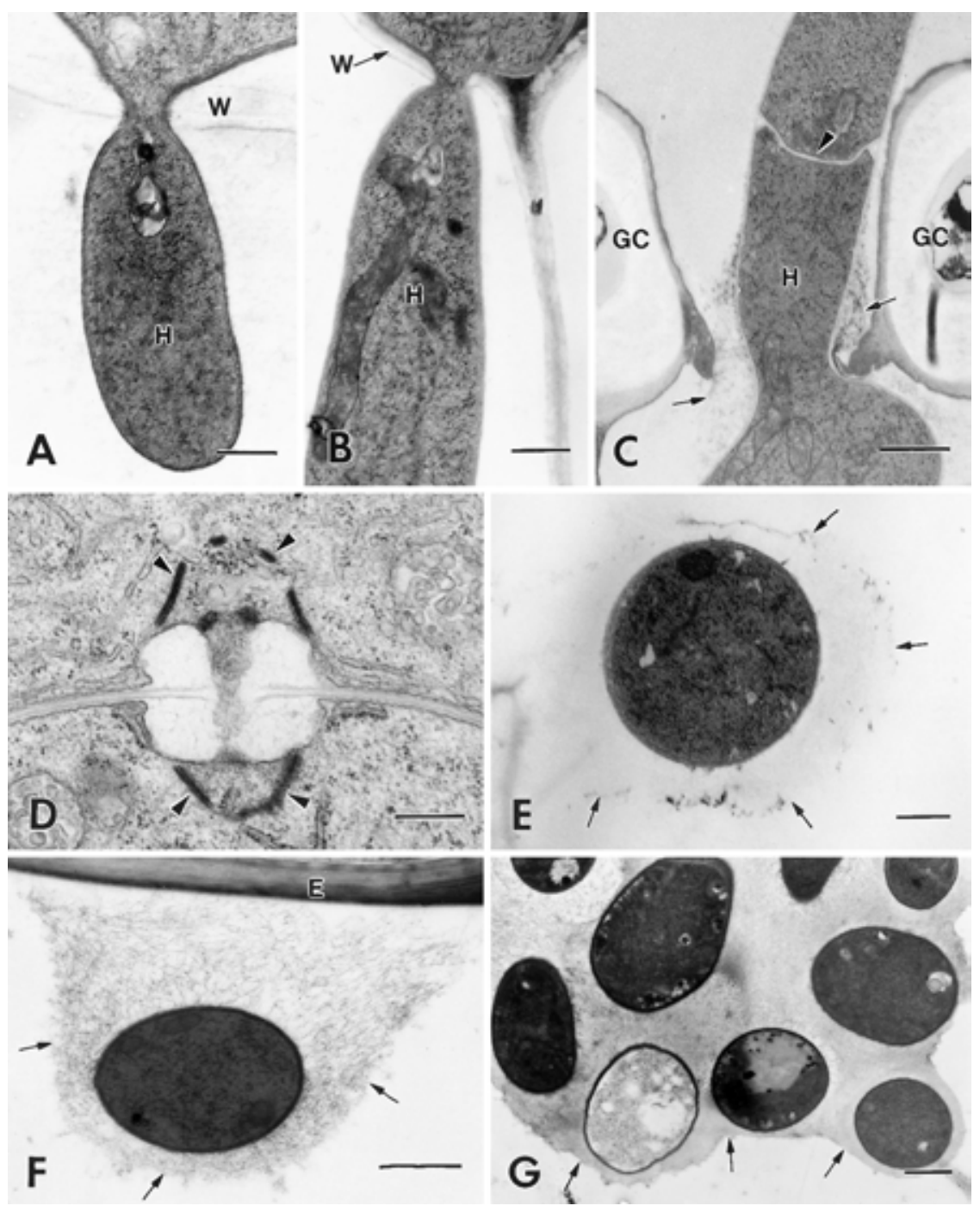

Fig. 7. Transmission electron micrographs of hyphae of isolate FB00-01 associated with leaves of tall fescue cv. Rebel III. A and B, Examples of two host cell wall penetration sites inside infected leaves. Each host cell wall is visible at W. Note the constricted nature of the hyphae $(\mathrm{H})$ at the penetration sites (arrows) and the absence host cell wall papillae. Bars $=0.5 \mu \mathrm{m}$. C, Portion of a longitudinal section of a hypha $(\mathrm{H})$ entering a leaf via a stomatal pore. Portions of the surrounding guard cells are visible at GC. A hyphal septum is shown at the arrowhead and some extracellular material (arrows) is visible on the hyphal surface. Bar $=1 \mu \mathrm{m}$. D, Near median longitudinal section of a septum. The septal pore cap is visible at the arrowheads. Bar $=0.3 \mu \mathrm{m}$. E, Cross section of a hypha on the outside of a leaf. A layer of extracellular material (arrows) surrounds the hypha. Bar $=1 \mu \mathrm{m}$. $\mathbf{F}$ and $\mathbf{G}$, Thicker sections of $\mathbf{F}$, a single hypha and $\mathbf{G}$, a group of hyphae surrounded by extracellular material (arrows). Bars $=1 \mu \mathrm{m}$.

and colonization by a fungus related to either L. fuciformis or Limonomyces roseipellis. Several reports $(1,7,15)$ have indicated that infection by $C$. fuciformis $(=$ Laetisaria fuciformis) was limited to penetration of stomatal openings. In contrast, Kaplan and Jackson (7) observed that isolates of A. fuciformis (= Limonomyces roseipellis) penetrated leaves of perennial rye grass via stomata and direct penetration of epidermal cells. Our failure to observe direct penetration by isolate FB00-01 may be a host-mediated response (tall fescue slow transition from chlorosis to a bleached straw-colored appearance.

\section{ACKNOWLEDGMENTS}

We thank S. Stephens for his technical assistance; and M. Mackiewicz, N. Donofrio, and T. Mitchell for assistance with DNA sequencing.

\section{LITERATURE CITED}

1. Bahuon, A. 1985. Factors in the infectious development and impregnation characteristics of Corticium fuciforme (Berk.) Wakef., the pathological agent responsible for red thread diseases in turf grasses. Pages 569-577 in: Proc. Fifth Int. Turfgrass Res. Conf. F. Lemaire, ed. INRA Publications, Paris.

2. Burdsall, H. H. 1979. Laetisaria (Aphyllophorales, Corticiaceae), a new genus for the teleomorph of Isaria fuciformis. Trans. $\mathrm{Br}$ Mycol. Soc. 72:419-422.

3. Burpee, L. L., and Goulty, L. G. 1986. Suppression of brown patch disease of creeping bentgrass by nonpathogenic Rhizoctonia spp. Phytopathology 74:692-694.

4. Couch, H. B. 1995. Diseases of Turfgrasses. Krieger Publishing Co., Malabar, FL.

5. Dellapota, S. L., Wood, J., and Hicks, J. B. 1983. A plant DNA minipreparation: Version II. Plant Mol. Biol. Rep. 1:19-21.

6. Horsfall, J. G., and Cowling, E. G. 1978 Pathometry: The measurement of plant disease. Pages 119-136 in: Plant Disease: An Advanced Treatise. Vol. 2, How Disease Develops in Populations. J. G. Horsfall and E. B. Cowling, eds. Academic Press, New York

7. Kaplan, J. D., and Jackson, N. 1983. Red thread and pink patch diseases of turfgrasses. Plant Dis. 67:159-162.

8. Kumar, S., Tamura, K., and Nei, M. 1993. Molecular Evolutionary Analysis, version 1.02. The Pennsylvania State University, University Park.

9. Martin, S. B. 1987. Rapid tentative identification of Rhizoctonia spp. associated with diseased turfgrasses. Plant Dis. 71:47-49.

10. Mims, C. W., and Vaillancourt, L. J. 2002 Ultrastructural characterization of infection and colonization of maize leaves by Colletotrichum graminicola, and by a $C$. graminicola pathogenicity mutant. Phytopathology 92:803-812.

11. Scheef, E., Casler, M., and Jung, G. 2003 Development of species-specific SCAR markers in bentgrass. Crop Sci. 43:345-349.

12. Scott, A. J., and Knott, M. 1974. A cluster analysis method for grouping means in the analysis of variance. Biometrics 30:507-512.

13. Smiley, R. W., Dernoeden, P. H., and Clarke, B. B. 1992. Compendium of Turfgrass Diseases, 2nd ed. American Phytopathological Society Press, St. Paul, MN.

14. Stalpers, J. A. 1978. Identification of woodinhabiting Aphyllophorales in pure culture Stud. Mycol. 16:1-248.

15. Stalpers, J. A., and Loerakker, W. M. 1982 Laetisaria and Limonomyces species (Corticiaceae) causing pink diseases in turf grasses. Can. J. Bot. 60:529-538.

16. White, T. J., Bruns, T., Lee, S., and Taylor, J. 1990. Amplification and direct sequencing of fungal ribosomal RNA genes for phylogenetics. Pages 315-322 in: PCR Protocols: A Guide to Methods and Applications. M. A. Innis, D. H. Gelfand, J. J. Sninsky, and T. J. White, eds. Academic Press, San Diego, CA 